\title{
A prospective study of efficacy and safety of mifepristone and vaginal misoprostol in termination of pregnancy up to 63 days of gestation
}

\author{
Mahima Jain*, Sonali Sharma
}

Department of Obstetrics and Gynecology, BJMC, Ahmadabad, Gujarat, India

Received: 25 November 2016

Accepted: 20 December 2016

\section{*Correspondence:}

Dr. Mahima Jain,

E-mail: drmahimajain@yahoo.co.in

Copyright: (C) the author(s), publisher and licensee Medip Academy. This is an open-access article distributed under the terms of the Creative Commons Attribution Non-Commercial License, which permits unrestricted non-commercial use, distribution, and reproduction in any medium, provided the original work is properly cited.

\begin{abstract}
Background: Illegal abortion is still one of the important causes of maternal mortality in India accounting for approximately $13 \%$. Medical Management of abortion is a non-surgical termination which does not require special facilities like operation theatre, hospital stay and thereby reduces complications associated with the same.

Methods: It is a prospective study done in a Tertiary care Government Hospital over a span from Jan 2015 to April 2016. After patient selection as per inclusion criteria and written informed consent after evaluating patients were enrolled in the study. In first visit Tab. mifepristone $200 \mathrm{mg}$. orally was given and advised to take Tab. misoprostol $800 \mathrm{mcg}$. Vaginally after 48 hours at home. They were counselled for side effects and asked to report in case of excess bleeding, pain, fever or no bleed for 24 hours of misoprostol. After 7 days follow up was done to ensure completion of abortion. Any additional drugs required were noted. Contraceptive advice is also given during these visits.

Results: In our study 60 cases were taken. Majority of women are between 20-29 years of age which is peak reproductive age. $61.1 \%$ women are of second parity. The success rate of medical methods is $96.6 \%$, two cases out of 60 underwent surgical evacuation and one was lost to follow up. Most common adverse effect noted is abdominal cramps. No patient required hospitalization. Additional Misoprostol was required in 4 cases. This method is highly acceptable $95 \%$ cases as it is non invasive and preferred to adopt the same in future if needed.

Conclusions: Patient participation, motivation, compliance, regular follow up visits, ability to record and report complications are the pillars on which the success of medical methods depends. Hence overall, it came out to be safe and effective method.
\end{abstract}

Keywords: First trimester medical methods for termination of pregnancy, Up to 63 days of gestation

\section{INTRODUCTION}

Unwanted pregnancy is a proxy indicator for the unmet needs for contraception. ${ }^{1}$ In India; women try a variety of remedies to deal with unwanted pregnancy including tablets, decoctions and visits to unsafe providers. Worldwide nearly 40 million abortions take place annually, of which approximately 10-22 million are illegal abortions. ${ }^{2,3}$

In India, unsafe abortion practices are an important cause of maternal mortality and morbidity. $13 \%$ of the pregnancy related deaths are attributed to unsafe abortions. ${ }^{1}$ The study is conducted with a purpose of ensuring safe women seeking the same with medical method i.e. drugs.

Medical Management of abortion is a non surgical termination which does not require special facilities like operation theatre, hospital stay and there by reduced complications associated with the same. Hence it is a safer method of choice for women in a developing country like India where medical facilities are at times costly and limited. 


\section{Aims and objectives}

1. To study efficacy of medical management of termination of pregnancy up to 63 days of gestation.

2. To study the side effects of the drugs used for medical termination of pregnancy.

3. To study the needs for add on methods in form of medical or surgical methods for first trimester termination of pregnancy.

4. To study acceptability of medical management of termination of pregnancy.

\section{METHODS}

This is a prospective study on 60 pregnant women with pregnancy up to 63 days of gestation opting for voluntary medical termination of pregnancy in Tertiary care Government hospital setting from Jan 2015 to April 2016. All underwent basic investigations in form of haemoglobin, blood group $\mathrm{ABO} / \mathrm{Rh}$ typing, urine (routine and microscopy). Due Ethical Committee clearance is obtained before onset of study. Drug used are Tab. Mifepristone 200mg. and Tab. Misoprostol $200 \mathrm{mcg}$. 4 tab. $(800 \mathrm{mcg})$ vaginally.

\section{Inclusion criteria}

1. Female seeking first trimester MTP with gestational age $\leq 63$ days ( 9 weeks).

2. Opting and giving consent for the study.

3. Age: $18-40$ years old.

4. Marital Status: married or unmarried.

\section{Exclusion criteria}

1. Patient not giving consent for medical method of termination of pregnancy.

2. Patients with previous scarred uterus like previous one or more cesarean section, past history of myomectomy or past history of hysterectomy.

3. Patients having absolute contraindications for prostaglandins, history of bronchial asthma, glaucoma, hypersensitivity to drugs, epilepsy.

\section{Method of collecting data}

An established protocol was followed which includes:

\section{First visit (day 1)}

- A detailed history taken and patient selection as per inclusion criteria.

- Initial pelvic examination

- Trans-vaginal sonography to confirm intra uterine pregnancy and exact gestational age.

- Basic investigation done. Anti D given to all Rh negative women.

- A written and informed consent taken in Form C.
- Patient explained about administration of Tab. Mifepristone 200mg. per oral.

- Follow up card is given and explained about what she needs to record.

- Counseling about pain and bleeding after first drug.

- She should report immediately to hospital in case of excess bleeding, fever, acute pain abdomen for which contact number is provided.

Second visit optional (day 3)

Almost all women opted for home administration of Tab. Misoprostol, hence 4 tab. i.e. $800 \mathrm{mcg}$ was kept vaginally after 48 hours at the same time as the first drug. She should report if no bleeding for 24 hours after misoprostol intake.

\section{Third visit}

Patient is asked to come for follow up after 7 days of Misoprostol intake. Clinical evaluation, history regards side effects noted. Pelvic examination and TVS done to ensure complete abortion. Candidates are counselled for contraception and cafeteria approach is given.

Outcome measured in terms of Complete and Incomplete Abortion. Failure is defined as the presence of gestational sac following drug administration.

\section{RESULTS}

Majority of cases $76.7 \%$ are in the age group of 20-29 years which is the peak reproductive age group.

Table 1: Demographic profile of cases.

\begin{tabular}{|lll|}
\hline Age in years & No. of cases $\mathbf{N}=\mathbf{6 0}$ & Percentage \\
\hline$<20$ & 2 & 3.3 \\
\hline $20-29$ & 46 & 76.7 \\
\hline$\geq 30$ & 12 & 20 \\
\hline
\end{tabular}

Table 2: Area wise distribution of cases.

\begin{tabular}{|lll|}
\hline Area & No. of cases $\mathbf{N}=60$ & Percentage \\
\hline Rural & 14 & 23.3 \\
\hline Urban & 46 & 76.7 \\
\hline
\end{tabular}

In our study $76.7 \%$ cases belong to urban area due to awareness of public and location of the hospital.

Table 3: Parity wise distribution.

\begin{tabular}{|lll|}
\hline Parity & No. of cases $\mathbf{N}=60$ & Percentage \\
\hline Primi & 6 & 10 \\
\hline Second & 37 & 61.7 \\
\hline Third & 10 & 16.7 \\
\hline Fourth & 6 & 10 \\
\hline$>4$ & 1 & 1.6 \\
\hline
\end{tabular}


Majority of women $61.7 \%$ are of second parity this is when female do not want future conception due to various reasons.

Table 4: Indications of MTP.

\begin{tabular}{|lll|}
\hline Indications & No. of cases $\mathbf{N}=\mathbf{6 0}$ & Percentage \\
\hline $\begin{array}{l}\text { Failure of } \\
\text { contraceptive }\end{array}$ & 6.7 \\
\hline $\begin{array}{l}\text { Socio economic } \\
\text { class }\end{array}$ & 38 & 63.3 \\
\hline $\begin{array}{l}\text { Unplanned } \\
\text { Pregnancy }\end{array}$ & 18 & 30 \\
\hline
\end{tabular}

In our study $63.3 \%$ of women wanted MTP due to lower or middle socio economic reasons.

Table 5: Period of gestation in the study.

\begin{tabular}{|lll|}
\hline Gestation & No. of cases $\mathbf{N}=60$ & Percentage \\
\hline Up to 6 weeks & 22 & 36.7 \\
\hline 6-7 weeks & 33 & 55 \\
\hline 7-9 weeks & 5 & 8.3 \\
\hline
\end{tabular}

As shown above 55\% cases had 6-7 weeks of gestation period at time of MTP.

Table 6: Side effects of drugs.

\begin{tabular}{|lll|}
\hline Side effects & No. of cases $\mathbf{N}=60$ & Percentage \\
\hline $\begin{array}{l}\text { Abdominal } \\
\text { cramps }\end{array}$ & 37 & 61.6 \\
\hline Nausea & 10 & 16.6 \\
\hline Vomiting & 6 & 10 \\
\hline $\begin{array}{l}\text { Excess } \\
\text { bleeding }\end{array}$ & 5 & 8.3 \\
\hline Diarrhoea & 00 & 00 \\
\hline
\end{tabular}

As per above data side effects like abdominal cramps, nausea, vomiting, excess bleeding are well tolerated and did not require hospitalization. Hence, it is safe and popular method of MTP among women.

Table 7: Efficacy of drug as per outcome.

\begin{tabular}{|lll|}
\hline Efficacy & No. of cases $\mathbf{N}=60$ & Percentage \\
\hline $\begin{array}{l}\text { Complete } \\
\text { abortion }\end{array}$ & 57 & 96.6 \\
\hline $\begin{array}{l}\text { Incomplete } \\
\text { abortion }\end{array}$ & 1 & 1.7 \\
\hline Failure & 1 & 1.7 \\
\hline $\begin{array}{l}\text { Lost to follow } \\
\text { up }\end{array}$ & 1 & 1.7 \\
\hline
\end{tabular}

As shown in the table our study had $96.6 \%$ success rate which is comparable with other studies. One women had incomplete abortion, one failure with continuation of pregnancy, both of which underwent surgical evacuation.
As shown above very few patients required additional drugs to treat minor side effects like fever, vomiting, bleeding. Thus it is a safe method of termination of pregnancy.

Table 8: Need for add on drug.

\begin{tabular}{|lll|}
\hline Drug & No. of cases & Percentage \\
\hline Tab Misoprostol & 4 & 6.6 \\
\hline Tab Rantac & 6 & 10 \\
\hline Tab Dicyclomine & 2 & 3.3 \\
\hline $\begin{array}{l}\text { Tab Ibuprofen/ } \\
\text { Paracetamol }\end{array}$ & 2 & 3.3 \\
\hline
\end{tabular}

The average induction-abortion interval is 3-6 hours as found in $69 \%$ cases.

Table 9: Induction-abortion interval.

\begin{tabular}{|lll|}
\hline Interval & No. of cases $\mathbf{N}=\mathbf{6 0}$ & Percentage \\
\hline Up to 2 hours & 10 & 17.2 \\
\hline 3-6 hours & 40 & 69 \\
\hline 6-10 hours & 8 & 13.4 \\
\hline
\end{tabular}

Table 10: Contraceptive method adopted after abortion.

\begin{tabular}{|lll|}
\hline $\begin{array}{l}\text { Contraceptive } \\
\text { method }\end{array}$ & No. of cases & Percentage \\
\hline Condoms & 39 & 65 \\
\hline OCP & 2 & 3.3 \\
\hline IUCD & 15 & 25 \\
\hline Tubal ligation & 2 & 3.3 \\
\hline Vasectomy & 1 & 1.6 \\
\hline
\end{tabular}

In our study post abortion IUCD kept in 15 women, 2 underwent laparoscopic sterilization and vasectomy opted by one case. Proper counselling in this regards is having a high impact amongst the population.

\section{DISCUSSION}

During this study out of 60 cases 57 had complete abortion. Hence the success rate is $96.6 \%$. The finding matched with other studies as follows: Kumar $\mathrm{S}$ et al (95.65\%), Grossman D et al (93.8\%), Das V, Jain S et al (96.67\%), Jain JK et al (95.8\%), Crenin MD (95.8\%), Whikoff B et al also studied safety, efficacy and acceptability of Medical abortion and found complete abortion rate of $91.4 \%$.(5). ${ }^{2,5-9}$

Hence irrespective of various regimens followed, medical abortion is a successful, safe, efficacious and clinically acceptable method for termination of first trimester pregnancy. Hence it can be concluded that medical method of termination of pregnancy with Mifepristone $200 \mathrm{mg}$. and vaginal Misoprostol $800 \mathrm{mcg}$. Is a safe and effective method of abortion. 


\section{CONCLUSION}

Our study with $96.6 \%$ success rate established that it can be used safely up to 63 days of gestation termination. Careful patient selection, evaluation and counselling are highly needed to attain this success rate safely. Secondly, the success rate depends on patient participation, motivation, compliance and eagerness to follow up. Hence it is mostly preferred by urban, educated population in upper and middle socio economic start. Common side effects are well tolerated hence the method has very high acceptability with $95 \%$ opting to adopt the same method in future if needed.

Funding: No funding sources

Conflict of interest: None declared

Ethical approval: The study was approved by the Institutional Ethics Committee of SMIMS

\section{REFERENCES}

1. Pathfinder International Handbook for primary care medical practitioners. 2003, pg. 4-91.

2. Das V, Jain S, Gupta HP. The Journal of Obst and Gynecology of India, Sept. 2005;55(5),454-6.

3. Padubiri VC, Daftary SN, Shaws Textbook of Gynecology $13^{\text {th }}$ edition, New Delhi, Elsevier, 2004: pg. 241.

4. Unsafe abortion Global and regional estimates of incidence of unsafe abortion and associated mortality in 2008, Sixth Edition, Geneva, World Health Organization, 2008.

5. Cheng L. Surgical versus medical methods for second trimester abortion. The WHO Reproductive Health Library, World Health Organization. 2008.

6. Revised edition of Guidelines for early medical abortion in India using Mifepristone and Misoprostol, WHO-CCR in Human Reproduction, AIIMS in collaboration with Ministry of Health and Family Welfare, GOI and Indian Council of Medical Research, 2007.

7. Suku MG, Pratap K. Miscarriage, Essentials of Obstetrics by Arulkumaran, Edition 4. 2013.

8. Grossman D. Medical methods for first trimester abortion: RHL commentary revised; 3 sept. 2004. The WHO Reproductive Health Library, Geneva: World Health Organisation.

9. Kumar S, Patreka M, Deshpande H. A Prospective Trial using Mifepristone and vaginal Misoprostol in termination of pregnancies up to 63 days of gestation - The Journal of Obstetrics and Gynecology of India. 2014;63(6):370-2.

Cite this article as: Jain M, Sharma S. A prospective study of efficacy and safety of mifepristone and vaginal misoprostol in termination of pregnancy up to 63 days of gestation. Int J Reprod Contracept Obstet Gynecol 2017;6:567-70. 